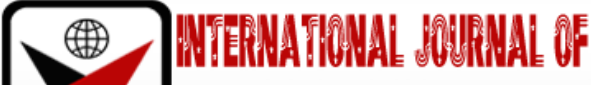

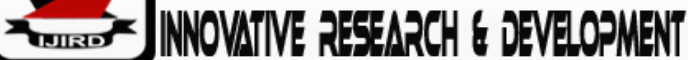

ISSN 2278-0211 (Online)

\section{An Exploration of Malaria Medication Decisions Making Process in Tanzania: A Case of Mbeya Region}

\author{
Blandina Kisawike \\ Lecturer, Department of Business Administration, \\ University of Iringa, Tanzania
}

\begin{abstract}
:
The purpose of this study is to explore the malaria medication decision making process in Tanzania. An exploratory research design was adopted which helped to discover ideas and insights underlying consumers' decisions on malaria medication. Purposive sampling was used to select 16 participants in this study. The findings from the study revealed that consumers have good knowledge on the causes and treatment of malaria disease. However, consumers were shown to differ in making the decision on malaria medication some consumers visited health centres, others pharmacists, others laboratory technician while others visited traditional medical practitioners. The findings of this study are expected to provide health professional bodies with knowledge about the decision-making process consumers' use while seeking malaria medication. This will help them to improve the health centres hence encourage Tanzanians to utilize them. Also, the findings are expected to provide useful knowledge to policy makers such as TMDA and government in general which will help them to have a productive conversation with traditional medical practitioners about how the traditional medicines are produced. Hence more research could be undertaken to find out the efficacy and standards of the traditional medicines. In addition, these findings are expected to educate Tanzanian consumers on the consequences of applying self - medication in treating malaria.
\end{abstract}

Keywords: Malaria, malaria medication, decision making process

\section{Background of the Research Problem}

The treatment and control of malaria pose a serious challenge. Yet, access to prompt and effective malaria treatment, a foundation of any malaria control strategy, is sub-optimal in many settings. An important part of strategies for combating malaria is reducing mortality and morbidity through early diagnosis and prompt treatment (Rønn, 1998) as cited by Kisawike (2015). This will, however, be influenced by factors related to cost, availability and cultural beliefs about the causes and effective cures (Oreagbaet al., 2005). The epidemiological, medicinal and entomological aspects of malaria and its consequences for the social and economic outlook of countries in which it is endemic are well documented (Rodriguez,1993). People seek treatment for malaria from a wide range of providers, including pharmacies, formal health centres/hospitals/dispensaries and traditional medicines. However, there are many problems with the treatment provisions. Hence, factors influencing malaria medication decision making process need to be investigated.

Reducing the human infectivity of the malaria parasite through early and effective treatment is still challenging. Different studies in Tanzania and other African countries on effective and prompt malaria treatment identified a number of challenges to malaria treatment in relation to health systems. The challenges identified were barriers to the successful malaria case management due to poor adherence to drug regimes, and underdosage in many households because of poverty and the fact that clinical cure of fever is what matters to many individuals (Mboeraet al., 2002); stock-out of the anti-malarial remedies especially in the public health centres (Lufesiet al., 2007; Silumbe, 2010; Mikkelsen-Lopez et al., 2014); drug sellers' knowledge on malaria medication (Nsimba,2007; Okekeet al., 2006; Brugha, 2002); shortage of qualified health workers (Maestad, 2006; Naickeret al., 2009; Kwesigaboet al., 2012) and poor quality of the anti-malarial remedies (Martin et al., 2008; Newton et al., 2006).

Also, the availability of different medications for malaria treatment such as domestic anti-malarial remedies, foreign anti-malarial remedies and traditional medicines has broadened choices of malaria treatments (Kisawike, 2015). Treatment seeking refers to a process by individuals and/or social groups for restoring health by using medical resources of all kinds (Muela, 2000). The decisions that patients make about health care have been shown to be influenced by many different factors. A study carried out by Gilson et al. (1994), in the Morogoro region of Tanzania, found that the highest ranked factors for treatment choices were availability of drugs, trust in the health care providers, high level of care, better follow up treatment and severity of problem. On the other hand, a study carried out by Wenzel (2011) in Shirati-Tanzania found that consumers valued both traditional and western medicine for treating their ailments. To Shirati people, western medicine was their first choice; however, consumers went for traditional medicine as their second alternative when the previous treatment given at the hospital did not cure them. The presence of different malaria medications, together with 
other factors such as geographical location, time and the availability of health facilities, have contributed to self-medication by a number of Tanzanians, which leads to resistance of malaria parasites to commonly-used drugs. Where there is drug resistance the use of anti-malarias can reduce parasite levels and eliminate symptoms without curing the patient (Warsameet al., 1999). The remaining parasites accumulate again over time and the symptoms return (Ellmanet al., 1998). This reduction in parasites followed by their recurrence, when combined with a retrospective diagnosis, causes misjudgements and delays in treating people with malaria (Ellmanet al., 1998).

Various studies have been conducted on malaria in Tanzania on topics such as acceptability of artermether-lumefantrine (ALU) as a first line anti-malarial treatment (Kabanywanyiet al., 2010); adoption of the new anti-malarial drug policy (Eriksenet al., 2005); improvements in access to malarial treatment in Tanzania after the switch to Arteminisinin Combination Therapy (ACT) (Alba et al, 2010); role of traditional healers in the management of severe malaria among children below five years (Makundiet al., 2006); obstacles to prompt and effective malaria treatment leading to low community coverage in rural districts (Hetzelet al., 2008); and other related studies. However, malaria medication decision making process on has not received attention.

\subsection{Research Objectives}

\subsubsection{General Objective}

To explore the Malaria Medication Decisions Making Process in Tanzania.

\subsubsection{Specific Objectives}

- To explore the Tanzanian ccommunity knowledge about Malaria disease.

- To investigate the malaria medication decision choice to Tanzania community.

\subsection{Research Questions}

- Do Tanzanian community have knowledge about malaria?

- What are the malaria medication decision choices to Tanzanian community?

\section{Literature Review}

\subsection{Consumer Decision Making}

Consumer decisions are the decisions that consumers make in a marketplace as buyers, payers and users. In general, these decisions consist of whether to purchase, what to purchase, when to purchase, from whom to purchase and how to pay for it (Shethet al., 1999). The decision process begins with the consumer recognising a problem to be solved. Consumers search for information about various alternative ways of solving their problem. After the consumer has all the information, he/she needs, he/she will think how to use this information to arrive at the choice. Then once the consumer has evaluated the alternatives, he/she makes the purchase decision. Finally, the consumer's decision process does not end with the purchase, as the experience of buying and using the product provides information that the consumer will use in future decision making (Engel et al., 1995; Shethet al,.1999; Schiffman and Kanuk, 2004). The consumer decision making process can be described as the process followed by an individual who has a specific need, and is evaluating alternative products or services with different brands and prices, in order to fulfil his/her needs.

Schiffmanet al. (2008:71-74) identify the consumer decision making views used by consumers: the economic view, the passive view, the emotional view and the cognitive view. In the economic view, consumers evaluate all the alternatives and choose the one with maximum utility/satisfaction. In the passive view, consumers are submissive to the self-serving interest and promotional efforts of marketers. That is to say, consumers do not make rational decisions based on utility but according to the manipulation of the marketers. The emotional view is where there are deep feelings or emotions attached to decisions, which mostly result in impulse buying. The last decision-making view is the cognitive view. According to this view, consumers make their decision based on how well the product /service will fulfil their needs and enrich their lives. Consumers actively search for products and services that will serve their goals. Out of the four views of consumer decision making, this study assumes that consumers are using the cognitive view of decision making, due to the nature of the study which deals with the impact of risk and involvement on choice of malaria medication.

There are factors influencing consumers in the decision-making process. These factors include past experience (Juliussonet al., 2005; Sagi and Friedland, 2007), demographic factors/individual differences (de Bruin et al., 2007; Reed et al., 2008), cognitive biases (Shah and Oppenheimer, 2008), belief in personal relevance (Acevedo and Krueger, 2004); and escalation to commitment (Juliussonet al., 2005. Five stages of the consumer decision making process are proposed (Schiffman and Kanuk, 2004; Engel et al., 1995; Blackwell et al., 2003. The mentioned factors are general in meaning and apply to different products. In this study, factors influencing consumers in making decisions on malaria medication were examined. Below, the consumers' decision-making process as shown in figure 1 and discussed by various authors is detailed. 


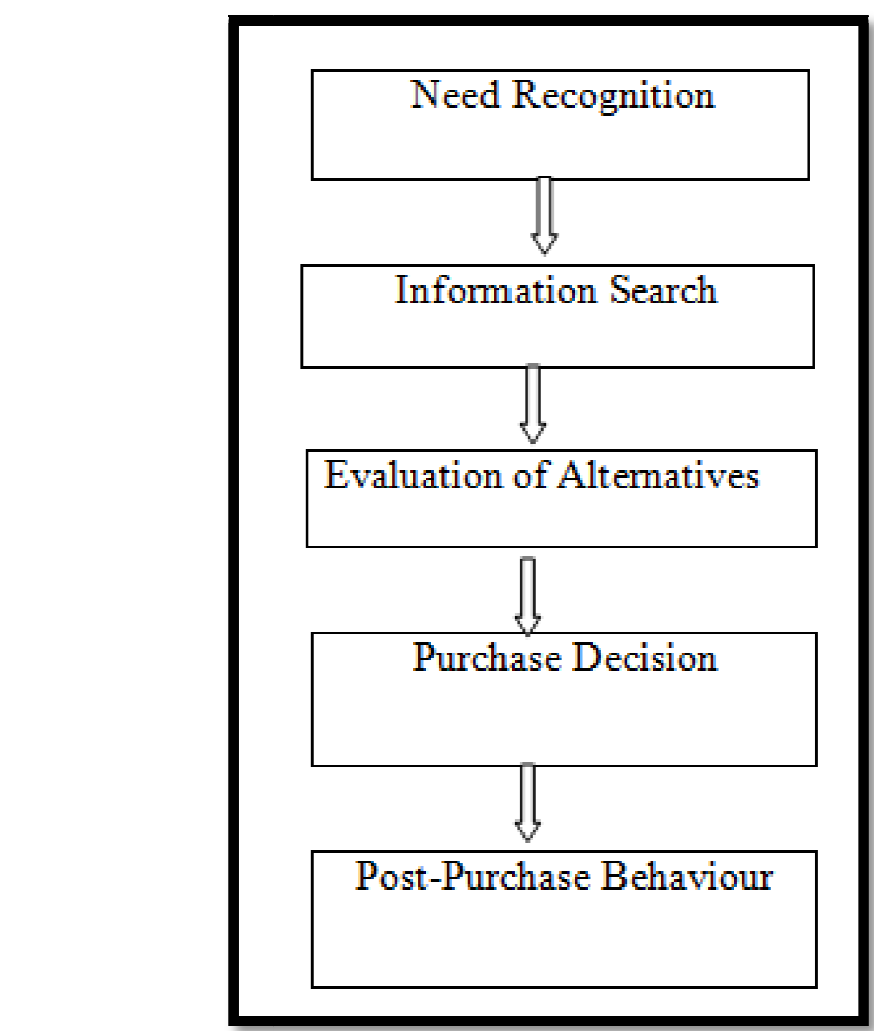

Figure 1: Consumer Decision Making Process

Source: (Schiffman and Kanuk,2004;Engel Et Al.,1995;Blackwell Et Al.,2003)

\subsubsection{Need Recognition}

Need recognition is the first stage of the consumer buying decision process. It occurs when the consumer realizes a need or want. This need arises when consumers recognize a difference between what they perceive as the current or actual state of affairs and the state of affairs they aspire to (Kisawike,2015). According to Hawkins et al. (1998) and Wyer $\mathrm{Jr}, 2008$ ) as cited by Galalae and Voicu (2013), the need recognition process begins once an individual identifies a need as a result of his/her exposure to internal or external stimuli which might prompt him/her to go on a quest for information about a means to satisfy the need, in an active/passive, conscious/ unconscious manner (Galalae and Voicu, 2013). Hawkins and Mothersbaugh (2010) outlined factors that affect the problem recognition step, such as social factors, cultural factors, reference groups, and environmental factors. Need recognition for malaria medication was explored.

\subsubsection{Information Search}

Once an initial need has been recognized, consumers will seek to obtain further knowledge in order to go through the purchasing process. At this stage, consumers will look for more information to underpin potential decisions. There are two types of information sources; internal and external information search. Internal search involves the consumer's memory about products, and external search includes word of mouth, store visits, trial and online social networking and social media (Kardes et al., 2011). Kotler and Armstrong (2008) identified four sources of information, which are personal, commercial, public, or experience sources. Various studies indicate that once consumers have high involvement in the purchasing process, they are likely to conduct a more active information search, and will be more willing to seek out detailed information from different sources (Engel et al., 1995; Erdemet al., 2005). Also, Marks and Olson (1981) proposed that consumers with a high level of product knowledge are complex in making their purchase decisions. In the same vein, Kempf and Smith (1998) suggested that consumers with a higher level of product knowledge are more diagnostic and better informed than those who have a lower level of product knowledge. This study identifies the information search and its impact on the choice of malaria medication.

\subsubsection{Evaluation of Alternatives}

Consumers evaluate the quality of the features of various products based on certain characteristics such as product attributes, degree of importance, brands, beliefs and expected satisfaction (Kotler and Armstrong, 2010). Given that there are a number of different brands in the marketplace, consumers have to create their own evoke set which consists of brands which are already in their minds (Solomon et al., 2010). Jobber (2007) added that the brands that are included in consumers evoke sets will have more opportunities to be selected by the consumers. In this stage, consumers consider which alternative would be the best to fulfil their need (Blythe, 2008). The criteria used by consumers in evaluating the anti-malarial remedies are identified in this study. 


\subsubsection{Purchase Decision}

Consumers have to choose one brand among several brands after evaluating their brand choices from the evaluation of alternatives stage (Bakshi, 2012). Consumers' product choices can be affected by various sources of information during the process of decision making (Solomon et al., 2010). Different factors and anticipated conditions can influence the decision (Hisrich, 2000). One such factor is a certain amount of risk that may be perceived by the consumers (Ueltschyet al., 2004; Chen and He, 2003). It can be said that when perceived risk falls below an individual's acceptance value, it has little effect on intended behaviour and is essentially ignored (Greatorex and Mitchell, 1993). On the other hand, an extremely high level of perceived risk can cause a consumer to postpone or avoid a purchase entirely (Dowling and Staelin, 1994). In this study, the decisions in purchasing the anti-malarial remedies were explored.

\subsubsection{Post-Purchase Behaviour}

The quality of the decision and how well the choice worked out becomes important in this stage of the process. Consumers start to compare their perceptions of the product with their expectations (Kardeset al., 2011). Even though the buying decision has finished, consumers often still evaluate their decisions. This is because they want to feel confident about their choices and to ensure that the quality of product can solve their problems or satisfy their needs (Bakshi, 2012). Jobber (2007) added that the quality of the product is a main determinant in the post-purchase evaluation. Positive, postpurchase behaviour is critical to the success of any company. Each transaction should be viewed as a starting point toward building a continuous relationship with customers (Durkin and Howcroft, 2003). The post- purchase behaviour in relation to anti-malarial remedies is a determinant in subsequent cycles of need recognition up to the purchase decision.

\subsection{Malaria Treatment Seeking Behaviour}

Consumers to date are exposed to a variety of health information which is transmitted by radios, television programme and well-designed health posters. These give them a wide choice of treatments when they are found with malaria parasites. According to Oberlander and Elverdan (2000), health-seeking behaviour is best seen as a process during which the beliefs and actions of the people in the immediate social environment of the sick person initiate treatment and subsequently evaluate the perceived outcome of the therapeutic actions. Treatment seeking refers to a process by individuals and/or social groups for restoring health by using medical resources of all kinds (Muela, 2000). The decisions that patients make about health care have been shown to be influenced by many different factors. A study carried out by Gilson et al. (1994), in the Morogoro region of Tanzania, found that the highest ranked factors for treatment choices were availability of drugs, trust in the health care providers, high level of care, better follow up treatment and severity of problem. A study in Kenya which was carried out by Mwabu (1986) divided factors into two categories: personal characteristics/demographic and qualities of health care providers. Personal /demographic characteristics included age, education, income, sex and religion. Quality of the health care providers was associated with the quality of treatment, accessibility; money and time spent for treatment and personal relationship.

In addition, the treatment seeking behaviour of patients was shown to be influenced by the nature of the disease. In a study conducted by Gilson et al. (1994) in the Morogoro Region of Tanzania patients stated that for certain diseases such as convulsions and measles, one should seek treatment from a traditional healer, whereas if one suffers from a fever or a headache he or she should go to the hospital. Similar results were found in a study of treatment seeking behaviour of patients with malaria; those with symptoms such as fever visited the hospital for western medicine, while those suffering from convulsions more often went to traditional healers (de Savignyet al., 2004).

A study carried out in Uganda by Tabuti (2006) shows that consumers differ in treatment seeking behaviour; there, consumer used modern anti-malarial remedies when they were found with malaria, by visiting the drug shops and buying the medicine (self-medication with modern anti-malarial medicine). A variety of reasons were stated by these respondents as to why they preferred modern medicine over traditional medicine. Some cited lack of relevant traditional knowledge to exploit herbal medicines for the treatment of malaria, while others believed that modern medicines are more effective. On the other hand, some consumers' preference was for self-medication with herbal medicine. Their attitudes were determined mainly by the fact that herbal medicines were free, readily accessible and/or were also more effective than modern medicines. However, consumers who preferred herbal medicine reported that if the first line of treatment was not effective, then the preferred option was to visit health facilities for modern medicine (Tabuti, 2006).

According to Onwujekweet al. (2009), people seek treatment for malaria from a wide range of sources ranging from itinerant drug sellers to hospitals, but they often resort to the unregulated private commercial sector, where treatment may be inappropriate, although access costs may be lower. The choice of multiple providers is also common, and patients often begin with self-treatment using drugs purchased through the commercial sector, and then seek care from formal health providers. If a patient is very ill, the public sector may be preferred because of the presence of more sophisticated equipment and a greater range of staff (Rønn, 1998). Patients may feel that private providers charge very high prices and are often unconvinced about the motivation of private providers, believing them to be primarily interested in generating income for themselves rather than in the welfare of their patients (Rosenberg et al., 1990). Also, the level of knowledge of different providers about malaria may strongly influence malaria treatment practices (Onwujekweet al., 2009). In a study carried out in South- East Nigeria to determine patent medicine dealers' perspectives on malaria, it was found that although the providers had fairly good knowledge about the causes and treatment of malaria, their treatment provision practices were sub-optimal. Also, it was found that there is a lack of knowledge about the factors that influence the type of treatment that healthcare providers provide for the treatment of malaria and how the information can be used to improve treatment provision (Onwujekweet al., 2009). Due to limited accessibility of health centres and performance of the modern anti-malarial remedies, patients find another alternative: using traditional medicines (TMs). 


\section{Methodology}

This study was carried out at Mbeya Region which is in the southern part of Tanzania. Mbeya is one of the regions that have high records of malaria suffering in Tanzania. In addition, Mbeya comprises consumers from different parts of Tanzania and it has the advantage of being close to two national borders, Malawi and Zambia which offers routes for importing medicines. The researcher found this city to be the best area to target as it helped the researcher to get answers to the research questions as well as meeting the research objectives.

This study was intended to discover ideas and insights on the malaria medication decision making process in Tanzania; therefore, an exploratory research design was employed. According to Sekaran and Borgie (2010), exploratory studies are undertaken to better comprehend the nature of the problem since very few studies might have been undertaken in that situation. Exploratory research has an advantage of flexibility and adaptability to change. This helped the researcher to obtain useful responses from the participants as the researcher adopted the flexibility of the study to explore ideas and insights on the malaria medication decision making process to Tanzanian consumers. Since an exploratory research design was concerned, qualitative research was adopted in this study.

The Interpretivist theoretical lens was adopted in this study. As the interpretivist paradigm seeks to understand the subjective reality of participants in a way that is meaningful for the participants themselves (Brand, 2009), the researcher acknowledged the different demographic characteristics studied and participants' subjective ways of deciding the malaria medication which suited their chosen criteria. By adopting an Interpretivist paradigm, the researcher assumed that the decision-making process on malaria medication is not an objective phenomenon with known properties or dimensions; hence, a subjective way of reasoning was needed. The adoption of the Interpretivistparadigm helped the researcher to recognize the wide interpretations of reality from the participants. In this study, respondents were viewed as peers or friends and an attempt made to discover hidden meanings, as opposed to measurement in the research (Proctor, 2003).

Considering the nature of this study, the targeted population for this research were Tanzanian consumers, clinical officers, traditional medical practitioners and pharmacists. This study explored the malaria medication decision making process in Tanzania. Obtaining deep information on these issues required participation of people with specific knowledge and experience: consumers who had chosen and used anti-malaria remedies, practitioners involved in diagnosing and prescribing, pharmacists who stock and supply medication and traditional medical practitioners who offer alternative treatments. Therefore, nonprobability sampling, specifically purposive sampling, was used in selecting the participants. Purposive sampling permits the researcher to decide which cases to choose that will be best able to answer the researcher's research questions and meet the researcher's objectives (Saunders et al., 2009). This strategy enabled the researcher to gain access to a variety of knowledge and experience relevant to different aspects of the research phenomenon in order to address the research questions and meet its objectives. Profiles of individual participants are shown in Table one. It should be noted that the participants' names listed in the table below are not the real names.

\begin{tabular}{|c|c|c|c|c|c|}
\hline Name & Sex & Age & Education & Location & Occupation \\
\hline Tula & F & 75 & Primary & Rural & $\begin{array}{c}\text { Traditional Medical } \\
\text { Practitioner }\end{array}$ \\
\hline Erick & M & 25 & Diploma & Urban & Businessman \\
\hline Alex & M & 35 & Primary & Urban & Taxi Driver \\
\hline Israel & M & 37 & Bachelor degree & Urban & Clinical Officer \\
\hline Ben & M & 79 & Diploma & Rural & Retired Pastor \\
\hline Bariki & M & 33 & Master & Urban & Assistant Lecturer \\
\hline Frank & M & 36 & Master & Urban & Accountant \\
\hline Neema & F & 33 & Master & Urban & Assistant Lecturer \\
\hline Jacob & M & 32 & Diploma & Urban & $\begin{array}{c}\text { Traditional Medical } \\
\text { Practitioner }\end{array}$ \\
\hline Emmanuel & M & 37 & Bachelor & Urban & Pharmacist \\
\hline Jesca & F & 64 & Primary & Rural & Farmer \\
\hline Atu & F & 47 & Primary & Urban & House wife \\
\hline John & M & 25 & Bachelor & Urban & Teacher \\
\hline Paul & M & 49 & Bachelor & Urban & Clinical Officer \\
\hline Amy & F & 26 & Bachelor & Urban & Public Relations Officer \\
\hline Tumpe & F & 40 & Certificate & Urban & Teacher \\
\hline
\end{tabular}

Table 1: Participants' Profile

According to the nature of the study, the sample size studied was 16 respondents which comprised 1 clinical officer, 1 pharmacist, 2 traditional medical practitioners and 12 consumers.

Qualitative data was obtained through in-depth interview. Collis and Hussey (2003) suggested that in-depth interviews are appropriate when it is necessary to understand the construct that the interviewee sees as a basis for his or her opinions and beliefs about a particular matter. In-depth interview is also appropriate if the aim of the interview is to develop an understanding of the respondent's world so that the researcher might influence it either independently or collaboratively.

Use of in-depth interview in this study helped the researcher to get an in-depth understanding on the malaria 
medication decision making process to Tanzanian consumers. This method of data collection was appropriate in this study as the researcher believed that interviewing individual participants on the studied phenomena would help in collecting rich information which would be full of the individual's subjective perception and experiences on evaluation of antimalarial remedies. An interview guide was prepared based on themes identified from the literature which the researcher believed would enable useful information to be obtained from the participants. Interviewees were informed about the aim of the interview session. The researcher obtained consent from the interviewees to participate in the study

The trustworthiness of the study was determined through credibility (in preference to internal validity), transferability (in preference to external validity/ generalisability), dependability (in preference to reliability) and confirmability (in preference to objectivity) as proposed by Lincoln and Guba (1985) as cited by Shenton (2004) and Kisawike (2015).

The thematic data analysis technique was used to analyse the collected data. Braun and Clarke (2006) defined thematic analysis as a qualitative analytic method for identifying, analysing and reporting patterns (themes) within data. It minimally organizes and describes the data set in rich detail. However, frequently it goes further than this, and interprets various aspects of the research topic. According to Nameyet al (2012), thematic analyses, as in grounded theory and development of cultural models, requires more involvement and interpretation from the researcher. Thematic analyses move beyond counting explicit words or phrases and focus on identifying and describing both implicit and explicit ideas within the data, that is, themes. Although, the procedures of analysing data by using the thematic analysis have been said to miss the reliability component in the study, nevertheless thematic analysis is useful in capturing the complexities of meaning within a textual data set. It is also the commonly used method of analysis in qualitative research (Nameyet al., 2012).

In analysing the obtained information, the researcher adopted the Braun and Clarke's guide to thematic analysis. The components or steps of the process are; becoming familiar with the data, generating initial codes, searching for themes, reviewing themes, defining and naming themes and producing the report (Braun and Clarke, 2006). A theme captures something important about the data in relation to the research question and represents some level of patterned response or meaning within the data set.

\section{Research Findings}

The aim of this study was to explore the malaria medication decision making process in Tanzania. Malaria is the most killing disease among Tanzanian communities; the proper medication is important in order to reduce the mortality rate. In this study, the knowledge of the malaria disease among Tanzanian communities and the malaria medication decision making process were explored.

\subsection{Tanzanian Community Knowledge about Malaria}

Malaria is an infectious disease that is caused by a parasite called Plasmodium. Patients get malaria from a bite of a type of female mosquito called Anopheles that carries the Plasmodium parasite to the liver then infects the patient's blood cells. In this study, Tanzanian consumers' knowledge concerning malaria was explored. It was found that most of the Tanzanian community had a good understanding of malaria causes, symptoms, treatment and preventive measures. However, the decision on how to get the malaria treatment was up to the individual consumer. Tanzanian consumers were shown to be capable of distinguishing malaria from other types of fever on the basis of signs and symptoms, which are high fever, headache, vomiting and flu-like symptoms.

"Headache, lack of energy and loss of appetite and high temperature, to me, are the signs of malaria" (Erick)

"I perceive having malaria when the muscles ache, I get tiredness, and headache; sometimes I fail even to drive my car" (Alex).

"When one of my family is found with symptoms such as diarrhoea, vomiting, flu, fever and tummy ache we believe that the particular person has the malaria parasite" (Jesca).

There is no doubt that Tanzanian consumers know the malaria symptoms. Their knowledge was compared with a description by the clinical officer.

"The common symptoms of patient with malaria are; fever, loss of appetite, headache, muscle aches, vomiting and diarrhoea (especially in children) and tiredness" (Paul).

The response from the clinical officer above revealed that Tanzanian consumers have knowledge concerning malaria symptoms since their responses were the same. However, he emphasized that consumers who experience the mentioned malaria symptoms should visit the health centre for a malaria test.

"If a patient is suffering from malaria-like symptoms, he must immediately get the malaria test done to confirm the infection" (Paul).

Visiting the health centre for a malaria test is vital for all consumers who have malaria symptoms, as this will help them to identify the infection a patient has and provide the right medication at the right time. Despite the documentation of numerous health compromising factors, some studies have emphasized the value of adequate knowledge of malaria in order to ensure that people apply preventive measures, and seek prompt and appropriate treatment for themselves and their dependents (Hlongwanaet al., 2011; Tyagiet al., 2005).

\subsection{Prompt Malaria Diagnosis and Medication}

Prompt malaria treatment is done through malaria diagnosis and testing. The malaria parasites are not easily seen by the human eye; only special equipment can easily identify the malaria parasites. In this study it was found that there is a need for consumers to seek a malaria test since this process is more technical and it needs qualified people and equipment 
to diagnose the disease. Malaria tests are done to diagnose whether the individual is suffering for malaria and to determine the type of malaria parasite.

"There are various diagnostic tests which can be done, but the most important one is a blood smear test. Thick and thin blood smears are prepared from the peripheral blood and are observed under microscope to check for malaria parasite. This test is known as a peripheral smear examination which provides information on the species, stage and the density of the parasites. This test is the most reliable one" (Paul).

Malaria is a medical emergency and needs to be treated as soon as possible. It can be seen that it is not possible for an individual to conclude if he/she is suffering from malaria just based on the malaria symptoms. This shows that consumers need to visit the health centre for diagnosis in order to know their health status and get treated.

"Your doctor will ask you about your symptoms and examine you. If your doctor suspects that you have malaria, he/she may do a blood test. This is to find out what type of parasite you have been infected with and how much there is in your blood. If your blood test is negative, you will still need to have two further blood tests over one to three days. This is because the levels of parasite in your blood can vary. For example, if you have taken anti-malarial medicines, the level of parasite may be too low to detect" (Paul).

Knowing the malaria symptoms is not a guarantee for an individual to be assured that he/she is suffering from malaria. This is because a person having malaria-like symptoms may not necessarily have malaria parasite, unless the blood test proves that. As noted by Kassianos (2001) malaria is sometimes misdiagnosed as influenza because of the symptoms of fever, headache and generalized aches and pains. Pyrexia is common, and some patients complain of nausea and vomiting, diarrhoea and abnormal cramps. Therefore, visiting the health centre for a malaria test is very important.

Also, Bell et al. (2006) supported the findings above by saying that, "early diagnosis and treatment is lifesaving".

Moreover, while malaria can be treated with medicines, it is important that a patient start treatment as soon as possible.

"A patient's treatment will depend on a number of things including what type of malaria you have. Also, the length of time that a patient's treatment takes will vary depending on how severe the patient's infection is" (Israel).

There are a number of things to consider when treating malaria, such as the type of malaria and the patient's infection. Treatment is possible for participants who are visiting the health centres early after detecting the malaria symptoms. According to Skeet (2005), malaria is treated with anti-malarial drugs and measures to control symptoms, including medications to control fever, anti-seizure medication when needed, fluids and electrolytes. The types of medication that are used to treat malaria depend on the severity of the disease and the likelihood of chloroquine resistance.

\subsection{Malaria Medication Decision Choice}

The decision-making process on malaria medication was found to be associated with a number of uncertainties. Therefore, each consumer made the decision on where and how to get the malaria medication based on his/her chosen criteria. Health centres, pharmacies, traditional medical practitioners (TMPs) and private laboratory services were the sources found to be most used by Tanzanian consumers when seeking malaria treatment. In this study, the decisions made by Tanzanians while seeking for malaria treatment formed choices of advice seeking on malaria treatment, which will be discussed in the next section.

\subsection{Choices of Advice Seeking on Malaria Medication}

Tanzanian consumers were shown to differ in advice seeking on malaria medication. The reasons governing the consumers' decision-making processes while seeking for malaria medication were explored in this study. As mentioned in the above section, health centres, pharmacists, private laboratory services and traditional medical practitioners were utilized by Tanzanian consumers for malaria medication.

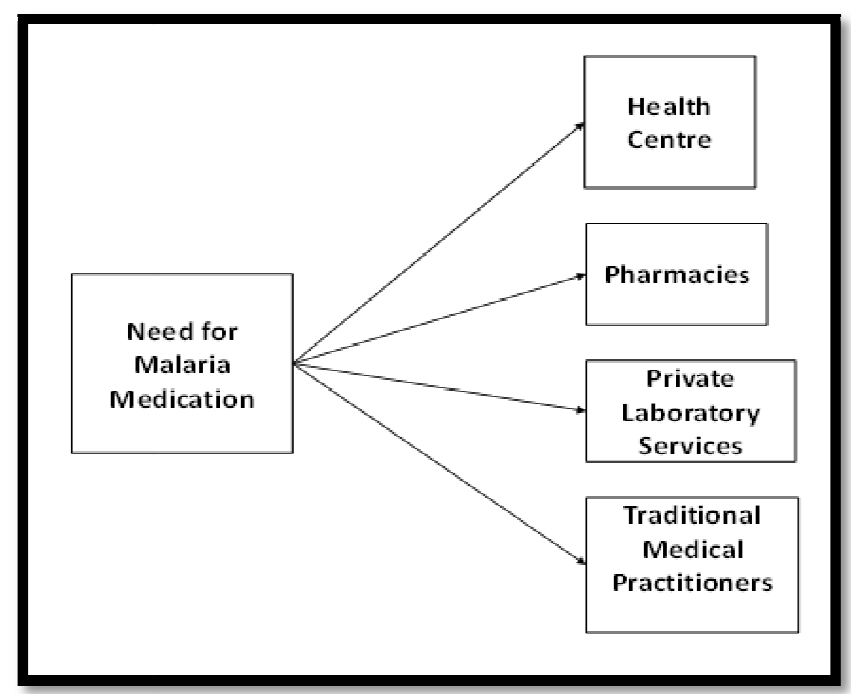

Figure 2: Choices of Advice Seeking on Malaria Medication Source: Kisawike (2015) 


\subsection{Health Centres}

Health centres were utilized by the most of Tanzanian consumers for malaria medication. Consumers who visited the health centres were tested for malaria parasite and clinical officers prescribed the right medication for their illness.

"When I feel I have malaria symptoms I usually visit the health centre to see the doctor for diagnosis, and when they find that I have malaria parasite the doctor prescribes anti-malarial drugs to use, then I go to the pharmacy to purchase the anti-malarial drugs" (Erick).

"In my family we used to suffer for malaria more than four times per year. So, when we found malaria symptoms we go to the hospital for a check-up, and when we were found to have malaria parasites, we go to the pharmacy to purchase the anti-malarial remedies" (Tumpe).

It is evident that Tanzanian consumers know the procedure to be used when seeking malaria medication. Visiting the health centre for malaria diagnosis is vital because it helps a patient to be sure about his/her health status. Also, it was found that malaria disease for most Tanzanians is a common disease since people suffer from it often; but despite its commonness, still some people were shown not to take it for granted; instead, they took appropriate measure for malaria treatment.

Surprisingly, it was found that even a family with relatives working as nurses in the district hospitals did not apply self-medication for malaria treatment; instead, they went to see a physician for malaria diagnosis.

"I am allergic to sulphur so when I have malaria symptoms, I go to the health centre for diagnosis when a physician detects that I have malaria parasite, I ask the doctor's advice about on anti-malarial remedy that shouldn't contain an element of sulphur. After getting the advice from the doctor I go to the pharmacy to purchase the recommended anti-malaria remedies. Also, when one of my family members has malaria symptoms, we send him/her to the health centre for proper diagnosis since we cannot diagnose ourselves. My wife is a nurse serving in one of the government hospitals, but she always insists we see the physician for diagnosis when we find malaria symptoms" (Ben).

The findings above show that consumers know the role of health workers and their responsibilities in malaria treatment. These consumers are seen to value their health by utilizing the qualified personnel in treating their bodies. By doing so their health will be strong and they will be able to participate in their daily activities, since they are physically fit.

Tanzania has a number of health centres, some public and other private owned. Public centres are utilized by all individuals who can easily access them because their treatment costs are subsidized by the government; therefore, most Tanzanians can afford to pay for those services. Private health centres are mostly utilized by some consumers who are at least at middle income level; their treatment costs are somewhat higher compared to the public health centres. Visiting the health centres for malaria diagnosis and treatment is highly advised by the government and other health stakeholders, as it helps a patient to know the extent to which he/she is affected by the malaria parasites, which in turn helps in determining the right medication for that particular level of infection. In this study it was found that some consumers, after recognizing the malaria symptoms, visited the health centres for malaria diagnosis and treatment. Consumers who could easily assess the health centres were satisfied with the health services provided, while some consumers faced some challenges in seeking treatment in the health centres. However; although Tanzanian consumers value the utilization of the health centres, it was found that there are number of challenges that hindered Tanzanians consumers from getting prompt malaria medication. The identified challenges were; cost of treatment, lack of malaria diagnostic tools, insufficient health care providers, drug shortage, malaria misdiagnosis and access to health centres. This calls upon the responsible Ministry to work on those identified challenges in order to encourage more Tanzanian to utilize health centres for effective malaria treatment.

\subsection{Pharmacies}

Seeking advice from pharmacists on malaria treatment was found to be the most common treatment seeking advice for most of Tanzanian consumers. The geographical location of the health centres, drug shortage in the public health facilities, and time used by consumers while waiting for malaria treatment were found to influence some consumers to visit the pharmacies directly when they found malaria symptoms.

"I am living $5 \mathrm{~km}$ far away from the health centre, and the transportation is a big problem in our village. So, when I find one of my family members has malaria symptoms, we visit the nearby small pharmacy in our village to ask for the drugs for malaria" (Jesca).

The findings above show that the geographical location of the health centres, especially for consumers living in the rural areas, forced them to visit pharmacists for treatment for malaria since they could not manage go to the health centre, due to high transportation cost. The advice they received from the pharmacist was highly valued by those consumers living in particular areas since they did not have an alternative for their treatment needs.

Also, some consumers were found to visit the pharmacy to purchase the anti-malarial remedies without being diagnosed, due to the time factor;

"I am a taxi driver, so a single minute is valuable. If I leave my car and go to the hospital to see the physician, I will definitely lose my customers. If I have malaria symptoms, I know I need to buy malaria medicines. So why pay for transportation to and from the hospital, pay for consultation with the doctor, pay for laboratory services and then pay to buy the drugs? In this case I don't see the need of going to the hospital because I will be wasting my time. So, I usually go straight to the pharmacy and ask for Metakelfin malaria medicine from Kenya. After taking it, I go on with my work" (Alex).

"I am well familiar with the malaria symptoms, so when I find I have malaria symptoms I usually visit the pharmacy to purchase the Orodar anti-malarial remedy from Kenya. I find I lost a lot of time visiting the hospital for malaria check-up, because you may find a long queue waiting to see the doctor. After seeing doctor then you need to queue for 
malaria check up at the laboratory. It will take sometimes more than 3-6 hours just for malaria treatment. So, to avoid this I decided to go to the pharmacy and purchase the said anti-malarial remedy." (Amy).

It was found that some consumers thought it a waste of time to visit the health centre for malaria check-up, so when they found malaria symptoms, they just visited the pharmacy to purchase anti-malarial remedies. However, the wastage of time was found to be caused by the insufficient number of professional doctors and pharmacists together with the procedures for malaria treatment. To a large extent these were shown to discourage many consumers from visiting the health centres, and so they sought advice from pharmacists.

However, despite the usefulness of pharmacists in providing health services to a large number of Tanzanians who cannot visit the health centres, it was found that some pharmacists are not knowledgeable enough to provide the right malaria medication, which causes some problems to the patients.

I bought the ALU anti-malarial remedy for my daughter who is three years old, I went back home and administered the medicine to her. After three hour she started crying, her body temperature was raised up and she was covered with a rush all over her body. I took her to the hospital with the medicine, then the doctor after looking at the medicine noticed that the given anti-malarial remedy had expired. He injected her and I was given another medicine (Frank).

Administering expired medicines is commonly practised in most pharmacies. Moreover, most Tanzanians do not look at the expiring dates on the medicines they are given by the pharmacists. This shows that Tanzanian consumers need to be advised on the importance of checking the expiry dates on the purchased medication before using it. Also, pharmacists have to be well trained to avoid administering expired anti-malarial remedies and other medication to patients, since it might cause other serious problems for patients.

"Some people who own the pharmacy are employing sales persons with little knowledge concerning the medication; they are looking for cheap labour instead of looking for qualified persons. Those sales persons with little knowledge concerning the different medication are polluting our field. Hence some people speak negative word of mouth about the dug shops" (Emmanuel).

It was found that regardless of the trust that consumers had in the pharmacists due to their availability and accessibility to most of consumers, some pharmacy owners employed drug sellers with no product knowledge. This resulted in administration of incorrect medication that harmed patients' health. Some consumers opted to use traditional medicine due to bad experiences with using the modern anti-malarial remedies, caused by misdirection by the pharmacists. Since drug stores/pharmacies are most trusted and helpful to a large number of consumers the pharmacy owners should hire qualified sales persons who will offer services effectively and ethically without harming the patients. In this way, more Tanzanian consumers would get the right treatment for malaria and so the mortality rates would be reduced.

Most Tanzanians largely depend on the services of the pharmacies. Pharmacies are located both in rural and urban areas. Their services are readily available because some pharmacies sell drugs until midnight. This has attracted a number of consumers to use them. In this study it was found that most of the participants, after recognizing the malaria parasites, visited pharmacies to purchase anti-malarial remedies, without malaria tests, while some patients visited the private laboratory services first for malaria check-ups after being recognized that they had malaria parasites they visited the pharmacies to purchase the anti-malarial remedies. Some pharmacists asked the patients about their symptoms for those who didn't visit the private laboratories for malaria check-ups and they administered the patient's medication based on the explanations given and other pharmacists administered anti-malarial remedies to patients based on the patient's choice.

Private pharmacies in Tanzania are among the supportive health stakeholders, since they are available almost all over the whole country. Even in the remote areas where there are no health facilities, one may find a local pharmacy that supports the population living in that area. Most patients preferred the pharmacists' services for a number of reasons, which were highlighted in the previous section, such as, long waiting time in the health centres due to insufficient number of health professional workers, drug shortage in the public health centres, geographical location, especially for rural consumers, malaria misdiagnosis and lack of malaria diagnostic tools in the public health facilities

In this study it was found that some pharmacies are served by drug sellers with no medical qualification. This has caused some patients to be adversely affected by the use of the administered anti-malarial remedies. There is a need for the government through the Ministry of Health and Social Welfare to develop policies that will guide all the pharmacies' owners to employ qualified pharmacists in order to increase the standards of medical provision. Also, all the pharmacies should be registered under the Tanzania Medicines and Medical Devices Authority (TMDA,) in order to facilitate follow up mechanisms.

The findings discussed above are consistent with Okekeet al. (2006) and Brugha (2002) who identified the reasons for pharmacy utilization by most patients: geographical accessibility, shorter waiting times, more reliable drug stocks, longer opening hours, greater confidentiality, more personable social interaction, ease of seeking advice, lower cost and flexible pricing policies and no separate fee charged for advice. Also, the risk of the poor qualification of the drug sellers was highlighted; in most cases, neither the drug seller nor the consumer is aware of the correct dosage and duration of treatment (Okekeet al., 2006; Gomes et al., 1998). Also, the risks of poor-quality treatment may be high, in view of the fact that uncomplicated malaria can proceed rapidly to severe disease and death, especially among young children who have yet to develop immunity (Greenwood et al.,1987).

Therefore, in order to improve community-wide effectiveness of malaria treatment, the popularity of homemanagement and the quality of treatment obtained from commercial shops need to be better addressed. Considerable improvement in case-management has been shown to be possible as a result of training private retailers in general shops 
(Marsh et al., 2004) and in drug stores (Hetzelet al., 2007). Also, the WHO (2010) noted the presence of consumers who are relying on pharmacists for their treatment for a variety of reasons and they emphasized that pharmacists in particular can play a key role in giving advice to consumers on the proper and use of medicinal products intended for selfmedication. WHO also suggested that it is important therefore to take this role into account both in their training and in practice (WHO, 2002).

\subsection{Private Laboratory Technicians}

Private laboratory technicians, especially in the urban area, provide check-ups for various diseases without prescribing or selling the medicines for a particular disease. This has attracted most Tanzanian consumers to value them because they found they are not trying to sell their medicines; instead, they are helping a patient to know his or her health status. In this study it was found that some consumers, when found with malaria symptoms, visited private laboratory technicians for malaria check-ups and when they were found with malaria parasites, some consumers went direct to the pharmacy to purchase the anti-malarial remedies, other consumers went to the health centre for consultations with their doctors while other consumers visited traditional medical practitioners for traditional medicines. The major reasons for visiting the private laboratory services were malaria misdiagnosis in the public health facilities and saving time.

"When I feel malaria symptoms, I visit the nearby laboratory service for malarial check-up. When the physician proves that I have malaria I visit the pharmacy to ask for orodar anti-malarial remedy from Kenya" (Amy).

Some consumers, after recognizing that they had malaria symptoms, visited the health centres for a malaria checkup and the results from the laboratory showed that they had no malaria parasites. The persistence of bodily weakness, however, made them visit a private laboratory for further malaria check-up and they were found to have malaria parasites.

After getting the results, they purchased anti-malarial remedies from the pharmacy and they recovered from their illness. Most of the public health facilities lack up to date laboratory equipment. As a result, the available laboratory equipment is yielding unreliable results, which discourages patients from using the public health facilities.

The other main factor in using laboratory services was time saving:

"Because of the long queue in the hospital, when I find malaria symptoms, I visit the private laboratory technicians for malaria check-up. If the result proves that I have malaria I visit the pharmacy to purchase Metakelfin malaria drugs from Kenya" (Bariki).

Long queues in both private and public health centres due to the insufficient number of health professional workers deter some consumers from utilizing health care facilities for malaria testing. As consumers know the importance of testing for malaria parasites before purchasing the malaria medication, they decide to visit private laboratory technicians for a malaria test then if they are found to have malaria parasites, they purchase the anti-malarial remedies from the pharmacies.

Malaria misdiagnosis, together with waiting time in the health centres, has encouraged most Tanzanians to utilize private laboratory services for malaria check-ups. It can be seen that some consumers are familiar with brands of antimalarials but they find it is vital to know their malaria status before purchasing anti-malarial remedies.

In addition, some consumers who valued traditional medicines also recognized the importance of a malaria test before visiting the traditional medical practitioners for malaria medication.

"For more than two years now I have been using the traditional medicines for various diseases including malaria.

Therefore, when I have the malaria symptoms I visit the private laboratory services for a malaria check-up, and when

I'm found with malaria parasite, I visit the traditional medical practitioners for malaria medication". (John).

Some consumers faced some problems when using some brands of anti-malarial remedies, and decided to look for an alternative, whereby they found traditional medicines suited them. Knowing the importance of malaria testing, they visited the private laboratory services, but after getting the results they went to traditional medical practitioners for malaria medication. This shows that Tanzanian consumers know the importance of doing a malaria test before looking for malaria medicines.

"I suffer from malaria often; I have been using different brands for malaria but after taking the medicine it takes me two to three months then I start feeling malaria symptoms. Last year my workmate introduced me to his mother-inlaw who supplies traditional medicines. I was interested and I stared using it. But before going for traditional medicines for malaria treatment I visit the private laboratory technicians for malaria test. After getting the results is when I ask for traditional medicine for malaria treatment" (Neema).

From the findings above it can be revealed that most consumers know the importance of testing for malaria parasites before seeking malaria medicines. Despite being discouraged by the performance of modern anti-malarial remedies, they still go for a malaria test, then after getting the results, look for traditional medicines for malaria treatment. Private laboratory services in Tanzanian environment as far as malaria disease is concerned were found to be the fastest and helpful sector to a number of Tanzanians. Most of private laboratory services in Tanzania are located in urban areas. In this study, consumers in urban areas when felt malaria symptoms were found to visit the private laboratories for malaria check-ups before purchasing anti-malarial remedies. Since the laboratory services provided the malaria check-ups for various diseases without prescribing or selling the medicines for a particular disease; this has attracted most Tanzanian consumers to value them because they found that these service providers are not after money instead, they help patients to know their health status.

In this study it was found that consumers who visited private laboratory technicians for malaria check-ups and found with malaria parasites, some consumers went direct to the pharmacy to purchase the anti-malarial remedies, other consumers went to the health centre for consultations with their doctors while other consumers visited traditional medical 
practitioners for traditional medicines. The major reasons for visiting the private laboratory services were malaria misdiagnosis in the public health facilities and saving time as discussed in earlier sections.

Since the private laboratory services has shown to support the Government's efforts in fighting against malaria in the Tanzanian community by helping patients to know their health status before purchasing the anti-malarial remedies; there is a need for the Ministry of Health and Social Welfare to find the means which can motivate a large number of health stakeholders to locate as many as possible laboratory services in order to supply the laboratory services to the entire population. Also, consumer living in the rural areas need to be considered as this service was found to be available in the urban areas only.

The findings above are supported by (Aidoo,2013) who found that malaria case management requires coordinated efforts by several healthcare professionals for laboratory tests to have a significant impact on malaria control and elimination, a paradigm shift is needed in patients care (Aidoo, 2013). Also, prompt and accurate diagnosis of malaria is the key to effective disease management, guiding the management of febrile patients and reducing the unnecessary use of anti-malarial drugs. High sensitivity of malaria diagnosis is important in all settings, and essential for the most vulnerable population groups in which malaria infection produces an acute illness that can rapidly progress to death. Existing laboratory services that provide malaria microscopy should be strengthened. Where microscopy in possible, RDTs should be introduced and appropriate quality assurance systems established (WHO, 2006). According to Dacombeet al. (2006), the role of any medical technology should be supplementary and contextual rather than a substitute for medical consultation. In the current situation, it has been funded that patient also demand laboratory investigations as part of medical care. In other words, in the current age 'laboratory medicines', medical care becomes comprehensive only with the support of basic laboratory facilities like laboratory support along with other infrastructural facilities are an important determinant influencing the utilization of health services.

\subsection{Traditional Medical Practitioners (TMPs)}

Traditional medical practitioners in the Tanzanian communities are found to be helpful to a large segment of the population in curing variety of diseases to a large extent. This is because the ratio of TMPs to population outnumbers that of health professional workers. In this study, it was found that TMPs were helpful to most consumers; some consumers visited TMPs for traditional medicines after being diagnosed, others went directly to the TMPs after recognizing the malaria symptoms. Most consumers who had used and were still using the traditional medicines were influenced by discouragement with the poor performance of the modern anti-malarial remedies.

"I lost my four children within one year because of malaria disease. They were administered with medicines from the hospital but it didn't work. I was so sad since they were grown up and they were able to generate income through businesses they used to perform. From that period, I started to learn how a traditional medicine can cure malaria. My grandparents used to cure different disease through traditional medicine, but I didn't capitalize on their knowledge. Since then, I went back home to seek advice on how I can prepare the traditional medicine, I started to practise and I managed. I have 30 years of experience in treating people suffering from malaria and other diseases. I, my husband, our remaining 3 children and our grandchildren, no one is using modern anti-malaria remedies. We all know the malaria symptoms so if any of us feel those symptoms they tell me and then I give them the medicines." (Tula).

Traditional medicines were found to be a solution to consumers who were discouraged by the poor performance of the modern anti-malarial remedies. The findings above show that some consumers decided to use traditional antimalarial remedies due to bad experiences after using modern anti-malarial remedies. Those experiences caused them to build negative attitudes towards the modern anti-malarial remedies, and hence trust the traditional anti-malarial remedies.

"It has been a long time since I suffered from malaria. Previously it was a normal issue for me to suffer from it. But three years back I was informed about the traditional medicine that is used to cure malaria. Then I visited the traditional medical practitioner who helped me with the traditional medicines and I was cured of malaria. Since then, when one of my family members has malaria symptoms, we visit the traditional medical practitioner and for sure his treatment is so fantastic since once you are given a dose it will take you more than a year to suffer again from malaria" (Atu).

I use traditional medicines for malaria and typhoid treatment, I was suffering from malaria and typhoid often and I was given tablets which made me feel tired every time I took them. I met with my friend in the college who introduced me to a man from the Seventh Day Adventists (SDA) who prepares traditional medicines and he helped me with the traditional medicines. The medicines are good since I am not getting any trouble that I used to experience when I was using the modern medicines (John).

Resistance of malaria parasites was common among Tanzanian consumers. Suffering from malaria every two to three months is normal to Tanzanian consumers. Taking anti-malarial remedies often made some consumers tired from using the medication; as a result, those who came across traditional medicines were found to be happy with this alternative way of curing malaria. Also, the preparation of traditional medicines was found to be natural with no preservatives added to the medication. This made consumers using the traditional medicines feel sure that the medicines they used were free from chemicals and so they would not come to any harm through using them.

"I use different plants together with food stuff materials such as garlic,ginger and other materials to prepare the tradtional medicines. During the preparation of traditional medicine I clean all materials needed with clean water, then I expose them to the sun until they dry out. Thereafter I process them in traditional ways to get powder, then I decant the processed medicine into read made containers and other plastic bags ready for use.In taking the medicine patients are required to take one teaspoon of the powder and mix it with warm clean water. The solution should be 
left for 3-5 minutes for it to function well then the patient can drink it.The doses are taken 3 times a day.Patients are advised not to take any alcoholic drinks while taking medicine to function in a proper way.I also advise my patients to have a balanced diet in their meals together with taking enough water, at least 2litres per day. The reason behind that is; the medicines are very strong, so their bodies need to be strong too.The medicine I am preparing is completely free from chemicals since all processes are carried out in traditional ways.My patients enjoy the treatment without facing any side effects after using the medicine offered to them" (Jacob).

"While preparing these medicines I use roots, barks, and leaves. Some plants, we used to eat their fruits without knowing that their roots/barks/leaves are used as part of medication. In preparing these medicines I take those plants materials and wash them, then I boil them for a half an hour. When it's ready I leave it so that it can cool down. Then I filter the extract ready for use. In my house I have a small refrigerator which I use to keep the prepared traditional medicine. The medicine I prepare is natural and free from chemicals since I don't add any chemicals for preservation. My patients take it as a juice twice a day, half a glass in the morning and in the evening too. I advise my patients not to take any alcohol during treatment" (Tula).

The materials used to prepare the traditional medicines are familiar to the users, since they are used as fruits and spices sometimes. Also, the preparation of those medications does not involve any chemicals, which attracts more consumers to use them and put more trust in them

From the findings above, it can be revealed that the traditional medical practitioners (TMPs) gave credence to the efficacy of TMs in the treatment of malaria as one major reason patients utilize them. Also, it was reported that TMs have the potency to cure malaria directly from the blood if the patient carefully takes the doses prescribed. The responses from

TMPs show that the TM are prepared in traditional ways without adding any chemicals, so consumers are asured that the consumption of the medicine will not affect their bodies compared to modern anti-malaria remedies, which have toxic components that can course some side effects to their health.

Traditional medical practitioners are among the unknown key stakeholders in the Tanzanian communities. Their practices are highly appreciated by a number of Tanzanians who find using traditional medicines worthwhile for them. In this study it was found that a number of consumers used traditional medicines after being discouraged by the performance of modern anti-malarial remedies. These consumers abandoned modern anti-malarial remedies after finding that traditional medicines worked for them. Traditional medical practitioners promoted their medicines by emphasising that the traditional medicines are natural, since they are prepared in traditional ways without adding chemicals. Therefore, they claim that their medicines are free from toxic substances and, hence, not harmful to the human body.

A number of Tanzanian consumers were shown to be satisfied with these services, especially those who had used a number of modern anti-malarials for their malaria disease and were not cured. Their satisfaction on consumption of the traditional medicines made them form a positive attitude toward traditional medicines, not only for malaria treatment but also for other diseases. The good word of mouth from consumers, who were satisfied with traditional medicines, has attracted a number of consumers to use the medicines; however, the uncertainties as to the efficacy, quality and standards of the medication deterred some consumers from using traditional medicines.

The Tanzania Medicines and Medical Devices Authority (TMDA,) as one of the key health stakeholders in Tanzania, acknowledge the practice of traditional medicine in treating different diseases. However, they warn patients to stop using the traditional medicines because those medicines are not scientifically proven. They have outlined the risk of using the traditional medicines, such as the resistance of malaria parasites to the medicines due to either overdosing or under doing. On the other hand, clinical officers reported that some consumers used traditional medicines for malaria treatment and when they found the medication did not work, they visited the health centres for more support. This causes delays in malaria treatment. Overall, there is a high level of uncertainty associated with the consumption of the traditional medicines by Tanzanian consumers.

From the findings above, it can be revealed that the practice of traditional medicine is helpful to a number of consumers as it was found to be the solution for several consumers who had suffered from the disease for long time without a complete cure by the use of modern anti-malarial remedies. However, the caution from the health stakeholders such as TMDA and clinical officers raised some doubts among Tanzanians who believed that traditional medicines are their main treatment; also, it discouraged some consumers who were thinking of starting using the medication after hearing good reports of such medication from those who had been cured by it.

In order to ease Tanzanian consumers' minds concerning the effectiveness of traditional medicines and their side effects, the government through the Ministry of Health and Social Welfare and TMDA needs to investigate the efficacy, standards and quality of the traditional medicines. Also, all the traditional medical practitioners should be registered and recognized in order to help the health stakeholders' governing bodies to monitor and evaluate their medical provision. In particular, the Tanzanian government needs to accept the practice of traditional medicine so that the services can be offered openly and the procedures followed by the traditional medical practitioners monitored. Also, there is a need for the government to foster collaboration between the traditional medical practitioners and the professional heath bodies to find smooth ways in which they can cooperate to reduce the malaria burden on Tanzanian communities in addition, the

Tanzania government needs to appreciate the natural resources it has and their usefulness in helping the population to fight against malaria, which is a burden to the nation.

The findings above are consistent with Adewunmi and Ojewole (2004) who assert that herbal products are often promoted to the public as being natural and safe. Herbal preparations are produced by subjecting herbal materials to extraction by fractionation, concentration, or other physical or biological processes. These herbal medicines are produced by different plant species involved in preparation. Also, one plant species may neutralize the toxic effects of other plant 
species, whilst allowing the active portion to alleviate fever and that is why herbal medicine is considered as having limited side effects in the process of treatment.

\section{Conclusions and Recommendations}

The findings from this study revealed that Tanzanian consumers are aware of the causes, symptoms and procedures to be used while seeking for malaria medication. The uncertainties on malaria medication influenced Tanzanian consumers to differ in the malaria medication decision making process. Each consumer decided where and how to get the malaria medication based to the criteria that were found to suit the consumer's choice. Choices of advice seeking on malaria medication was identified in this study; some consumers visited health centres for malaria treatment, others visited pharmacies directly to purchase anti-malarial remedies without a malaria diagnosis, and other consumers visited private laboratory technicians for a malaria test and thereafter purchased the anti-malarial remedies, while other consumers visited traditional medical practitioners to purchase traditional medicines for malaria treatment. This is to say, it is not necessary for consumers to use the five decision making processes as proposed by Schiffman and Kanuk (2004); Engel et al. (1995) and Blackwell et al. (2003). The nature of product or service will determine the decision process to be used by a consumers while purchasing a particular product or service.

This study has contributed to knowledge in several areas of consumer behaviour on medical products. These contributions will also be vital to the future researchers as can be used to identify their research gaps and add to their literature. Knowing the choices consumers made in getting malaria medication and their reasons governing their decisionmaking process will help policy makers to identify areas for improvement in order to smoothen health provision to the Tanzanian community and other developing countries where malaria is endemic and thereby reduce the mortality rate which is caused by the poor health services provided.

\section{References}

i. Aidoo, M. (2013). "Factoring quality Laboratory Diagnosis into the Malaria Control for sub-Saharan Africa". Am J Trop Med Hyg, Sept 4, Vol.89, No.3:403-406.

ii. Alba, S., Hetzel, M.W., Goodman, C., and Dillip, A. (2010). "Improvements in Access to Malaria Treatment in Tanzania after switch to artemisinin combination therapy and the introduction of accredited drug dispensing outlets: a provider perspective". Malaria Journal, Vol.9:164.

iii. Acevedo, M., and Krueger, JI. (2004). “Two egocentric sources of the decision to vote: The voter's illusion and the belief in personal relevance". Political Psychology, Vol.5, No.1:115-134. DOI: 10.1111/j.1467-9221.2004.00359.x.

iv. Bakshi, S. (2012). "Impact of gender on consumer purchase behaviour". Journal of Research in Commerce and Management, Vol.1, No.9:1-8.

v. Bell, D., Wongsrichanalai, C., and Barnwell, J.W. (2006). "Ensuring quality and access for malaria diagnosis: how can it be achieved?"Nat Rev Microbiol, Vol.4:S7-S20.

vi. Blackwell, R.D., Miniard, P.W., and Engel, J.F. (2003). Consumer Behavior. Orlando, FL: Harcourt.

vii. Blythe J. (2008). Consumer Behaviour. London: Thomson.

viii. Brand, V. (2009). 'Empirical Business Ethics Research and Paradigms Analysis'. Journal of Business Ethics,86:429449.

ix. Braun, V., and Clarke, V. (2006). "Using thematic analysis in psychology”. Qualitative Research in Psychology, Vol.3, No.2:77-101. ISSN 1478-0887.

x. Brugha, R.Z. (2002). "Improving the quality of private sector delivering of public health services: challenges and strategies". Health Policy Plan, 13:103-120.

xi. Chen, R., and He, F. (2003). "Examination of brand knowledge, perceived risk and consumers' intention to adopt an online retailer". Total Quality Management \& Business Excellence, Vol.14, No.6: 677.

xii. Collis,J., and Hussey,R.(2003).Business Research: A practical guide for undergraduate and postgraduate students (2nd edn.). Basingstoke: Palgrave Macmillan.

xiii. Dacombe,R.R., Squire,S.B., Ramsay, A.R.C., Banda,H.T., and Bates,I. (2006). "Essentials Medical Laboratory Services: their rolein delivering equitable healthcare in Malawi". Malawi Medical Journal, Vol.18, No.2:77-9.

xiv. de Bruin, W.B., Parker, A.M., and Fischhoff, B. (2007). "Individual differences in adult decision-making competence". Journal of Personality and Social Psychology, Vol.92, No.5:938-956. DOI: 10.1037/0022-3514.92.5.938.

xv. Dowling, G.R., and Staelin, R. (1994). "A model of perceived risk and intended risk-handling activity", Journal of Consumer Research, Vol.21, and No.1: 119-34.

xvi. Durkin, M. G., and Howcroft, B. (2003). "Relationship marketing in the banking sector: the impact of new technologies”. Marketing Intelligence \& Planning, Vol.21, No.1: 61-71.

xvii. Ellman, R., Maxwell, C., Finch, R., and Shayo, D. (1998). "Malaria and anaemia at different altitudes in the Muheza district of Tanzania: childhood morbidity in relation to level of expo-- sure to infection". Ann. Trop. Med. Parasitol, Vol.92:741-753.

xviii. Erdem, E., Keane, M.P., Öncü, T.S. Strebel, J. (2005). “Learning about computers: An analysis of information search and technology choice". Quantitative Marketing and Economics, Vol. 3, No.3:207-246.

xix. Engel, J.F., Blackwell, R.D., and Miniard, P.W. (1995). Consumer Behavior. International ed. Florida: Dryden.

xx. Eriksen,J., Nsimba, $\quad$ S.E.D.,Minzi, $\quad$ O.M.S.,Sanga,A.J., $\quad$ Petzold,M., $\quad$ Gustafsson,L.L., $\quad$ Warsame,M.Y., $\quad$ and Tomson,G.(2005).'Adoption of the new antimalarial drug policy in Tanzania - across-sectional study in the community". Tropical Medicine and International Health, Vol.10, No.10:1038-1046. 
xxi. Galalae, C., and Voicu, A. (2013)."Consumer Behaviour Research: Jacquard Weaving in the Social Sciences".Management Dynamics in the Knowledge Economy, Vol.1, No.2:277-292.

xxii. Gilson, L., Alilio, M., and Heggenhougen, K. (1994). "Community satisfaction with primary health care services: An evaluation undertaken in the Morogoro region of Tanzania". Social Science \& Medicine, Vol.39, No.6:767-780.

xxiii. Gomes, M., Wayling, S., and Pang, L. (1998). "Interventions to improve the use of anti-malarials in south-east Asia: an overview". Bull World Health Organ, 76:9-19.

xxiv. Greenwood, B.M., Bradley, A.K., Greenwood, A.M., Byass, P., Jammeh, K., Marsh, K., Tulloch, S., Oldfield, F.S., and Hayes, R. (1987). "Mortality and morbidity from malaria among children in rural area of the Gambia, West Africa".Trans R Soc Trop Med Hyg, Vol. 81:478-486.

xxv. Greatorex, M., and Mitchell, V.W. (1993). "Developing the perceived risk concept Proceedings". Marketing Education Group Conference, Vol.1:405- 415.

xxvi. Hawkins, I., Best, R. J., and Coney, K. A. (1998). Consumer Behavior: Building marketing strategy. New York: Irwin/McGraw-Hill.

xxvii. Hawkins, D.I., and Mothersbaugh, D. L. (2010) Consumer Behavior: building marketing strategy (11th edn.). New York: McGraw-Hill Irwin.

xxviii. Hetzel,M.W., Alba,S., Funkhauser,M., Mayumana,I., Lengeler,C., Obrist,B., Nathan,R., Makemba,A.M., Mshana,C., Schulze, A., and Mshinda, H.(2008). "Malaria risk access to preventation and treatment in the paddie of Kilombero Valley,Tanzania". Malaria Journal,Vol.7,No.7:1-13.

xxix. Hetzel, M.W., Iteba, N., Makemba, A., Mshana, C., Lengeler, C., Obrist, B., Schulze, A., Nathan, R., Dillip, A., Alba, S., Mayumana, I., and Mshinda, H. (2007). "Understanding and improving access to prompt and effective malaria treatment and care in rural Tanzania: the ACCESS Programme". Malaria Journal, Vol.6:83.

xxx. Hisrich, R. (2000).Marketing. New York:Barrons.

xxxi. Jobber, D. (2007). Principles and Practice of Marketing. (5th edn.). Berkshire: McGraw-Hill Education.

xxxii. Hlongwana, K. W., Mabaso, M. L., Kunene, S., Govender, D., and Maharaj, R. (2009). "Community knowledge, attitudes and practices (KAP) on Malaria in Swaziland: A country earmarked for Malaria elimination". Malaria Journal, Vol.8,No.1: 1-8.

xxxiii. Jullisson, E.A., Karlsson, N., and Garling, T. (2005). "Weighing the past and the future in decision making". European Journal of Cognitive Psychology, Vol.17, No.4:561-575. DOI: 10.1080/09541440440000159.

xxxiv. Kabanywanyi, A.M.,Lengeler,C.,Kasim,P.,King'eng'ena,S.,Schlienger,R.,Mulure,N., and Genton,B. (2010). "Adherence to and acceptability of artemether-lumefantrine as first-line anti-malarial treatment: evidence from a rural community in Tanzania".Malaria Journal, Vol. 9:48 doi:10.1186/1475-2875-9-48.

xxxv. Kardes, F.R, Cronley M.L, and Cline T.W. (2011). Consumer Behaviour. South-Western.

xxxvi. Kempf, D.S., and Smith, R.E. (1998). "Consumer Processing of Product Trial and the Influence of Prior Advertising: A Structural Modelling Approach". Journal of Marketing Research, Vol.35, No.3:325-338.

xxxvii. Kisawike, B (2015). How Country of Origin, Consumer Ethnocentrism and Consumer Xenocentrism Impact upon Risk and Involvement in the Malaria Medication Decision Making Process in Tanzania. PhD Thesis, Hull-United Kingdom.

xxxviii. Kotler, P., and Armstrong, G. (2008). Principles of Marketing. (12thedn.). New Jersey: Prentice-Hall.

xxxix. Kotler, P., and Armstrong, G.(2010).Principles of Marketing (13th edn.).. India: Prentice Hall.

xl. Kwesigabo, G., Mwangu, M.A., Kakoko, D.C., Warriner, I., Mkony, A.C., Killewo, J., Mcfarlane, S.B., Kaaya, E.E., and Freeman. P. (2012). "Tanzania's health system and work force crisis”. Journal of Public Health Policy, 33:S35-S44.

xli. Lincoln, Y. S., and Guba, E. G. (1985). Naturalistic inquiry. Newbury Park, CA: Sage

xlii. Lufesi, N., Andrew, M., and Auresnes, I. (2007). "Deficient supplies of drugs for life threatening diseases in an African Community”. BMC Health Serv. Res, 7:86.

xliii. Mæstad, O. (2006). "Human Resources for Health in Tanzania: Challenges, Policy Options and Knowledge Gaps". CMI Report. Chr. Michelsen Institute (CMI).

xliv. Makundi. E, A., Malebo, M. H., Mhame, P., Kitua, A.Y., and Warsame, M. (2006)."Role of traditional healers in the management of severe malaria among children below five years of age: the case of Kilosa and Handeni Districts, Tanzania". Malaria Journal, Vol.5:58 doi: 10.1186/1475-2875-5-58.

xlv. Marks, L.J., and Olson, J.C. (1981). "Toward a Cognitive Structure Conceptualization of Product Familiarity". Advances in Consumer Research, Vol.8, No.1:145-150.

xlvi. Marsh, V.M., Mutemi, W.M., Willetts, A., Bayah, K., Were, S., Ross, A., and Marsh, K. (2004). "Improving malaria home treatment by training drug retailers in rural Kenya".Trop Med Int Health, Vol.9:451-460.

xlvii. Martin, B. A. S., Wentzel, D., and Tomczak, T. (2008). "Effects of susceptibility to normative influence and type of testimonial on attitudes toward print advertising". Journal of Advertising, Vol.37, No.1: 29-43.

xlviii. Mikkelsen-Lopez1, I., Shango, W., Barrington, J., Ziegler, R., Smith, T., and deSavigny, D. (2014). "The challenge to avoid anti-malarial medicine stock-outs in an era of funding partners: the case of Tanzania". Malaria Journal, $13: 181$

xlix. Muela, S. H., Mushi, A. K., and Ribera, J. M. (2000). "The paradox of the cost and affordability of traditional and government health services in Tanzania". Health Policy and Planning, Vol.15, No.3: 296.

1. Naicker, S., Plange- Rhule, J., Tutt, B.C., and Eastwood, J.B. (2009). "Shortage of healthcare workers in developing countries-Africa" .Ethnicity and Disease: 19.

li. Newton, P.N., McGready, R., Fernandez, F., Green, M.D., and Sunjio, M. (2006). "Manslaughter by Fake Artesunate in Asia-Will Africa Be Next?” PLoS Med. 2006;3(6):e197Research;Dar es Salaam Tanzania. 
lii. Mboera, L.E.G., Kamugisha, M.L., Malima, R.C., Mushi, A.K., Msuya, F.H., Masawe, T., and Kitua, A.Y. (2002). "Malaria prevalence and health seeking behaviour among communities of the lowlands and highlands of Gonja, Same District, north-eastern Tanzania". Tanzania Health Research Bulletin, Vol. 4, 47-53.

liii. Mwabu, G. M. (1986). "Health care decisions at the household level: Results of a rural health survey in Kenya". Social Science \& Medicine, Vol.22, No.3:315-319.

liv. Nsimba, S.E., and Rimoy, G.H. (2005). "Self-medication with chloroquine in a rural district of Tanzania: a therapeutic challenge for any future malaria treatment policy change in the country". Journal of Clinical Pharmacy and Therapeutics, Vol.30:515-519.

lv. Oberländer, L.,and Elverdan, B. (2000). "Malaria in the United Republic of Tanzania: cultural considerations and health-seeking behaviour". Bull World Health Organ, 78:1352-1357.

lvi. Okeke, T.A., Uzochukwu, S.C., and Okafor, H.U. (2006). "An in-depth study of patent medicine sellers' perspective on malaria in rural Nigerian Community". Malaria Journal, 5;97.

lvii. Onwujekwe, O., Kaur, H., Dike,N., Shu, E., Uzochukwu, B., Hanson,K.,Okoye, V., and Okonkwo,P.(2009). "Quality of anti-malarial drugs provided by public and private healthcare providers in south-east Nigeria".Malaria Journal, Vol.8:22 doi: 10.1186/1475-2875-8-22.

lviii. Oreagba, A.I.C.C., and Mabadeje, A.F.B. (2005). "Prescribing patterns of anti-malarials in Public and Private Health Facilities in Lagos State". Malaria in Africa Sci. J, Vol.2:17.

lix. Reed, A.E., Mikels, J.A., and Simon, K.I. (2008). "Older adults prefer less choice than young adults". Psychology and Aging, Vol.23, No.3:671-675. DOI: 10.1037/a0012772.

lx. Proctor,T. (2003).Essentials of Marketing Research, Essex; Pearson Education Ltd.

lxi. Rønn, A.M. (1998). "Drug policy and drug resistance in East Africa. In: Blegvad L, Ringsted F, eds. Health care systems in Africa. Patterns and perspectives. Copenhagen, North-South Co-ordination Group (University of Copenhagen)". ENRECA Health Network, 105-110. 9. Bruce-Chwatt LJ.

lxii. Rosenberg, R., Andre, R.G., and Ketrangsee. S. (1990). "Seasonal fluctuation of Plasmodium falciparum gametocytaemia".Trans R Soc Trop Med Hyg, Vol. 84:29-33.

lxiii. Sagi, A., and Friedland, N. (2007). "The cost of richness: The effect of the size and diversity of decision sets on postdecision regret". Journal of Personality and Social Psychology, Vol.93, No.4: 515-524. D0I: 10.1037/00223514.93.4.515.

lxiv. Saunders, M., Lewis, P., and Thornhill, A. (2009). Research methods for business students (5th edn).Harlow: Prentice Hall Financial Times.

lxv. Schiffman, L.G., and Kanuk, L.L. (2004). Consumer Behavior (8th edn.). Upper Saddle River: Pearson Education Prentice-Hall NJ.

lxvi. Schiffman, L.G., Kanuk, L.L., and Hansen, H. (2008). Consumer behaviour: A European Outlook. Prentice Hall.

lxvii. Sekaran, U., and Bougie, R. (2010). Research methods for business: A skill building approach (5th edn.). West Sussex, UK: John Wiley \& Sons Ltd.

lxviii. Shenton, A. K. (2004). "Strategies for ensuring trustworthiness in qualitative research projects". Education for Information, Vol.22:63-75.

lxix. Silumbe, R.S. (2010). Pharmaceutical Management and Prescribing Patterns of Anti-malarial Drugs in the Public Health Facilities in Dar es Salaam, Tanzania. Dissertation.Muhimbili University of Health and Allied Sciences.

lxx. Sheth, J., Mittal, B., and Newman B. (1999). Consumer Behavior and Beyond. NY: Harcourt Brace.

Ixxi. Solomon, M., Bamossy, G., Askegaard, S., and Hogg, M. (2010). Consumer Behavior: Buying: A European Perspective (4th edn.). Financial Times Press.

lxxii. Tabuti, E. (2006). "Herbal medicine used in the treatment of malaria in Uganda: A case of Buiope Country" The Garden Club of America.

lxxiii. Tyagi, P., Roy, A., and Malhotra, M. S. (2005). "Knowledge, awareness and practices towards malaria in communities of rural, semi-rural and bordering areas of east Delhi (India)." Journal of Vector Borne Diseases, Vol.42, No.1:30-35.

lxxiv. Ueltschy, L.C., Laroche, M., Tamilia, R.D., and Yannopoulos, P. (2004), "Cross-cultural invariance of measures of satisfaction and service quality". Journal of Business Research, Vol. 57, No. 8:901-12.

Ixxv. Warsame, M., Kilimali, V.A.E.B., Wernsdorfer, W.H., Lebbad, M., Rutta, A.S., and Ericsson, O.C. (1999). "Resistance to chloroquine and sulfadoxine-pyrimethamine in Plasmodium falciparum in Muheza district, Tanzania". Transactions of the Royal Society of Tropical Medicine and Hygiene, Vol.93:312-313.

Ixxvi. Wenzel, T.L. (2011). "Western and Traditional Medicine Use Practices in Shirati, Tanzania”. Western and Traditional Medicine in Shirati, Tanzania, spring.

lxxvii. WHO. (2006). Guidelines for the Treatment of Malaria. Geneva, Switzerland.

lxxviii. WHO. (2010). Guidelines for the treatment of malaria (2nd edn.). Geneva

lxxix. Wyer, R. Jr. (2008). "Role of Knowledge Accessibility in Cognition and Behaviour. Implications for Consumer Information Processing, in Haugtvedt, C.P., Herr, P.M., and Hardes, F.R. (eds)”. Handbook of Consumer Psychology, Lawrence Erlbaum Associates. 